\title{
Encapsulation of Silver Nanoparticles in a Polystyrene Matrix by Miniemulsion Polymerization and Its Antimicrobial Activity
}

\author{
R. Betancourt-Galindo, C. Cabrera Miranda, B. A. Puente Urbina, \\ A. Castañeda-Facio, S. Sánchez-Valdés, J. Mata Padilla, L. A. García Cerda, \\ Y. A. Perera, and O. S. Rodríguez-Fernández
}

Departamento de Materiales Avanzados, Centro de Investigación en Química Aplicada, Boulevard Enrique Reyna Hermosillo no. 140, 25253 Saltillo, COAH, Mexico

Correspondence should be addressed to C. Cabrera Miranda, ccabrera1603@gmail.com

Received 29 March 2012; Accepted 7 May 2012

Academic Editors: L. Baia and C.-L. Hsu

Copyright (c) 2012 R. Betancourt-Galindo et al. This is an open access article distributed under the Creative Commons Attribution License, which permits unrestricted use, distribution, and reproduction in any medium, provided the original work is properly cited.

Surface-modified silver nanoparticles (NAg) were encapsulated into a polystyrene (PS) matrix by in situ miniemulsion polymerization. Silver nanoparticles were modified with 3-aminopropyltrimethoxysilane (APTMS) that acts as a coupling agent and costabilizer in the polymerization reaction. The PS-Nag nanocomposites synthesized via miniemulsion polymerization were made at two different concentrations of the initiator $\left(0.7\right.$ and $2.5 \mathrm{~g} / \mathrm{L}$ in $\left.\mathrm{H}_{2} \mathrm{O}\right)$; at higher concentration of the initiator the conversion and efficiency of encapsulation increases, and the average particle size decreases. The PS-NAg composites showed excellent antimicrobial performance toward bacteria such as Escherichia coli and Staphylococcus aureus.

\section{Introduction}

Polymer nanocomposites represent a new alternative to conventionally filled polymers. Nanocomposites exhibit markedly improved properties when compared to the pure polymers or their traditional composites. These properties include better mechanical properties, barriers to different gases, thermal stability, and flame retardant enhancements [1-5]. Recently, nanoparticles as $\mathrm{Ag}, \mathrm{TiO}_{2}$, and $\mathrm{ZnO}$ have shown excellent antimicrobial properties $[6,7]$. The antibacterial potential of silver nanoparticles has attracted great interest in the last years [8]. However, nanoparticles cannot be directly used for antimicrobial purposes without any modification. The application of nanoparticles varies widely based on their physical properties like apparent density, surface area, and morphology, which are strongly related to the preparation method.

Polymers are found to be very effective support for stabilization of nanoparticles. Inorganic-polymer hybrid microspheres have attracted great attention due of the different characteristics that the material can exhibit such as chemical resistance and mechanical behavior [9-12]. The properties of nanocomposites are greatly influenced by the dispersing degree of nanoparticles in the polymer matrix and the interfacial adhesion between components. There are several heterophase processes that allow the formation of polymeric nanoparticles in water; the most well-known method is the emulsion polymerization technique, which is used in many industrial applications. However, this technique is not well suited to the encapsulation of preformed polymeric or inorganic materials. In contrast, miniemulsion polymerization process is a very versatile technique for the formation of a broad range of polymers and structured materials in confined geometries [13]. This technique is a particularly attractive way to obtain polymer nanoparticles with uniform size $[14,15]$. Miniemulsions consist of small, stable, and narrowly distributed droplets in a continuous phase, usually obtained by applying high shear, either by ultrasonication or high-pressure homogenizers. The high stability of the droplets is ensured by the combination of the amphiphilic component, the surfactant, and the costabilizer, which is soluble and homogeneously distributed 
in the droplet phase. The costabilizer has a lower solubility in the continuous phase than the rest of the droplet phase and, therefore, builds up an osmotic pressure in the droplets (it is, therefore, also called an osmotic pressure agent) counteracting the Laplace pressure [16]. Such small droplets can then act as nanocontainers in which reactions can take place, either inside the droplets or at the interface of the droplets, resulting in most cases in the formation of polymer nanoparticles [17-19]. The interaction between the polymer and inorganic component plays an important role in the inorganic-polymer hybrid microspheres preparation [20]. An effective route to enhance this compatibility is by selecting the right agent to modify the surface properties of nanoparticles. In order to increase the encapsulation, efficiency of the hydrophilic nanoparticles is important to improve the hydrophobicity of the particle surface, which is obtained throughout the functionalization using a coupling agent. Tang and Dong used aminopropyltriethoxy silane (APTES) in the surface modification of silver nanoparticles to improve the dispersion and adhesion, when they were incorporated into a polymer matrix achieving affinity with the monomer [10]. Furthermore, according to Landfester [16], silanes can act as costabilizers in the miniemulsions formulation.

In this work, we studied the encapsulation of silver nanoparticles into a polystyrene matrix using miniemulsion polymerization. The effect on polymerization kinetics with 2,2'-azobisisobutironytrile (AIBN) as initiator and cetyltrimethyl ammonium bromide (CTAB) as surfactant was studied. In addition, the antimicrobial activity of the PSNag nanocomposites against Escherichia coli and Staphylococcus aureus strains was evaluated.

\section{Experimental}

2.1. Materials. Commercial (NAg) silver nanoparticles with an average particle size less than $30 \mathrm{~nm}$ (99.5\% pure), from SkySpring nanomaterials, were used in this study. 3aminopropyltrimethoxy silane (APTMS) (97\% pure) was used as a coupling agent, and octane with a $98 \%$ of purity was used as dispersion media. Cetyltrimethyl ammonium bromide (98\% pure) from Aldrich, which was previously recrystallized in an ethanol-acetone mixture, was used as surfactant. Also, hexadecane (HD) (99\% pure) was used as costabilizing agent. Styrene (St), methacrylic acid (99\% pure), and 2,2-azobisisobutironytrile (AIBN) from Aldrich Co. were used as monomer, comonomer, and initiator, respectively. Deionized water was used as solvent.

2.2. Surface Modification of Silver Nanoparticles. Surface modification was carried out using a weight ratio of $1: 0.5$ of NAg: APTMS. The reaction was made as follows: NAg and APTMS were added into $50 \mathrm{~mL}$ of octane, and the mixture was refluxed at $80^{\circ} \mathrm{C}$ for $6 \mathrm{~h}$ with stirring. The result solution was separated by decantation, and the solid was dried overnight at $80^{\circ} \mathrm{C}$ for its subsequent characterization.

2.3. PS-Nag Nanocomposites Preparation. The modified silver nanoparticles were encapsulated by miniemulsion polymerization using HD as costabilizing agent and varying the surfactant and initiator contents. The polymerization was performed in a $100 \mathrm{~mL}$ glass reactor; a surfactant/water $\left(\mathrm{CTAB} / \mathrm{H}_{2} \mathrm{O}\right)$ micellar solution was prepared by stirring for 30 min. A mixture of initiator, modified NAg nanoparticles, and styrene monomer was dispersed using ultrasound for $3 \mathrm{~min}$ and then was added into the glass reactor with the micellar solution The solution was sonicated for $2 \mathrm{~min}$ in order to achieve a stable miniemulsion and better NAg nanoparticles dispersion. Polymerization reaction was conducted under $\mathrm{N}_{2}$ atmosphere at $80^{\circ} \mathrm{C}$ and $430 \mathrm{rpm}$ of agitation. Methacrylic acid was added to improve the stability and compatibility of the solution. Samples were taken at different times in order to determine the reaction kinetic, using hydroquinone as an inhibitor. These samples were lyophilized for further characterization. The conversion rate $(\% \mathrm{C})$ was calculated using the following equation:

$$
\text { Conversion rate }(\%)=\frac{\text { Polymer fraction }}{\text { Monomer fraction }} * 100 \text {. }
$$

The encapsulation efficiency (\%EE) was calculated according to the procedure described by Tang et al. [21]. This involves the latex particle precipitation by centrifugation at $12,000 \mathrm{rpm}$ for $30 \mathrm{~min}$. The solution was carefully separated from the residue, and the stable compound particles were washed with deionized water and toluene. This operation was repeated until a relatively clear solution was obtained. The encapsulation efficiency was calculated according to the following equation:

$$
\text { Encapsulation efficiency }(\%)=\frac{D}{E} * 100 \text {, }
$$

where $D$ is the weight of the PS-Nag nanocomposite, and $E$ is the amount of polymer. The amount of polymer was determined by weight loss using thermogravimetric analysis.

2.4. Characterization. FTIR spectra of the modified silver nanoparticles and the PS-Nag nanocomposites were recorded in $\mathrm{KBr}$ pellets on Nicolet Magna-IR Spectrometer 550. The size and morphology of the nanocomposites were determined in a JEOL JSM7104F scanning electron microscope (SEM) with a STEM modulus.

2.5. Antimicrobial Test. Antimicrobial properties of PS-Nag nanocomposites were tested against Escherichia coli and Staphylococcus aureus strains. The test organisms were grown on nutrient agar plates by evenly spreading over the entire surface of the agar plates. The plates were incubated at $37^{\circ} \mathrm{C}$ for $24 \mathrm{~h}$. After the incubation process, $100 \mu \mathrm{g}$ of the PSNag nanocomposite was placed on each bacterial growth plate. Antimicrobial activity was determined by measuring the diameter of the zone of inhibition (in $\mathrm{mm}$ ) surrounding the PS-Nag nanocomposites. Each experiment was repeated three times. The antimicrobial activities were based on percentage inhibition calculated by using the average diameter of the bacterial colony on the growth medium compared with their respective control as follows:

$$
\% \text { inhibition }=\frac{(A-B)}{A} * 100,
$$




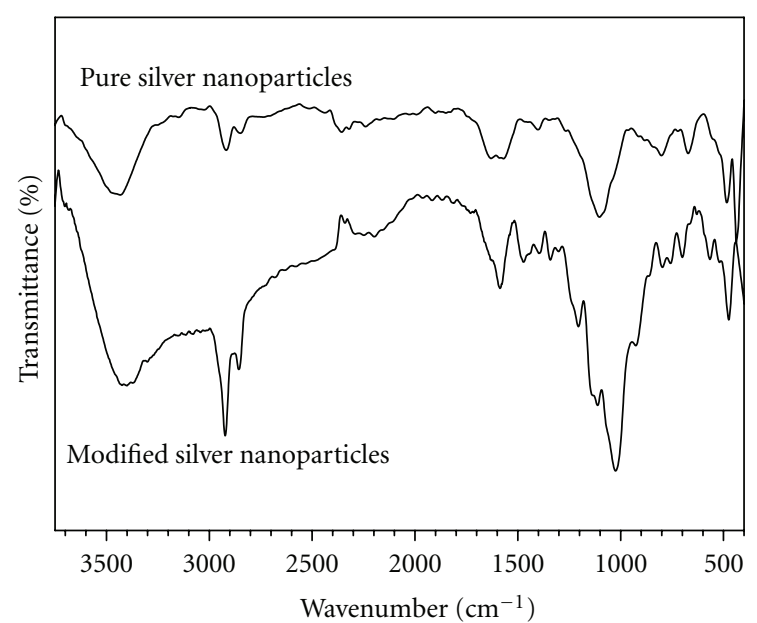

FIGURE 1: FTIR spectra for the pure and modified silver nanoparticles.

where $A$ is the average diameter of growth of organisms in the control, and $B$ is the average diameter of growth of organisms in the test plates.

\section{Results and Discussion}

To appreciate the binding mechanism of the surface modification of the silver nanoparticles, FTIR spectra of the pure silver and modified silver nanoparticles were examined as shown in Figure 1. For the pure silver nanoparticles, a band was observed at $3500 \mathrm{~cm}^{-1}$ that correspond of the stretching of the $\mathrm{N}-\mathrm{H}$ bond and two other shoulder peaks at $1600 \mathrm{~cm}^{-1}$ and $1200 \mathrm{~cm}^{-1}$ related to the stretching of the $\mathrm{C}=\mathrm{O}$ bond and the flexion of the $\mathrm{N}-\mathrm{H}$ bond. Similar results can be observed in the modified silver nanoparticles; in addition, bands at $1100-1050 \mathrm{~cm}^{-1}$ correspond to the $\mathrm{Si}-\mathrm{CH}_{3}$ bond that appears and also at $960 \mathrm{~cm}^{-1}$, a band corresponding to the $\mathrm{Si}-\mathrm{OH}$, and $\mathrm{Si}-\mathrm{O}$ stretching bonds are observed, and the presence of these bands confirms that the silver is effectively covered with the aminosilane. These results are in good agreement with those reported previously by Rodríguez et al. [22], who made the surface modification of magnetic nanoparticles with a similar silane compound using a molar ratio of $1: 0.5$ (nanoparticles : silane).

To achieve the encapsulation of inorganic nanoparticles, such as calcium carbonate, titanium dioxide, magnetite, silica, and silver, among others, in a hydrophobic matrix (organic), it is necessary that the nanoparticles surface becomes hydrophobic, either before or during their incorporation into the monomer phase [23]. Considering this, APTMS/surface-modified NAg nanoparticles in $1: 0.5$ weight ratio were used in order to promote the encapsulation process. The silane allows the grafting of polymer during the initial stages of polymerization [24]. Methacrylic acid (MMA) was added to obtain a surface with defined amounts of carboxylic acid groups that will allow the copolymerization process with the styrene monomer. Also it has been reported that the carboxylic groups provide stability to the polymeric particles and good interaction with the modified NAg particles [25-27].

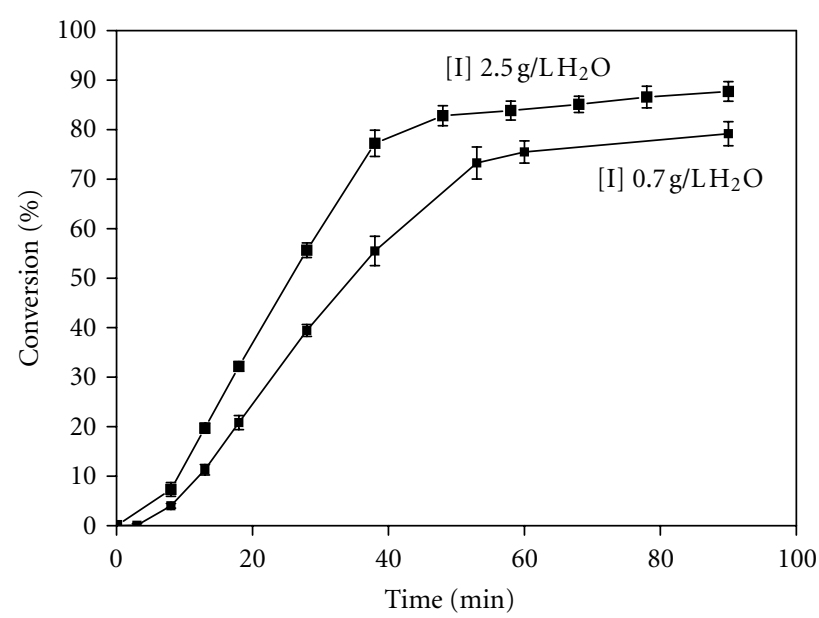

FIGURE 2: Conversion-time curves of miniemulsion polymerization of styrene at two different concentrations of the initiator.

Figure 2 shows the conversion curves of the polymerization reaction at two different concentrations of the initiator; as expected, the \% conversion increases with increasing initiator concentration [I]. The polymerization rate at $2.5 \mathrm{~g} / \mathrm{L}$ of AIBN was higher than that at $0.7 \mathrm{~g} / \mathrm{L}$. In both cases the conversion of styrene reached over $75 \%$ after $90 \mathrm{~min}$ of reaction. The miniemulsion polymerization rate depends on the rate of radical entry into the monomer droplets. Under the experimental conditions, the increment in the entry rate of radicals into the monomer droplets may have had a large effect on the polymerization rate, so the polymerization rate at $0.25 \mathrm{~g} / \mathrm{L}$ of the initiator was higher.

Table 1 summarized the results of encapsulation efficiency $(\% \mathrm{EE})$, conversion rate $(\% \mathrm{C})$, and average particle diameter for both polymerizations systems. The \%EE increases proportionally with the $\% \mathrm{C}$, due to the higher polymer content in the nanoparticles, which is corroborated by the results shown in Figure 2, indicating that a high efficiency of polymerization has been achieved. On the other hand, particle size distribution, it can be seen a decrease in the particle size as monomer conversion increases. According to the results, this effect contributes to the increase in \%EE and $\% \mathrm{C}$. When the costabilizing agent was added in the reaction system and initiator concentration increases, the efficiency of encapsulation and conversion are improved due to that secondary nucleation is avoided by the desorption of radicals into the aqueous phase.

Figure 3 shows the FTIR spectra of PS and PS-Nag nanocomposites synthesized. The $\mathrm{C}-\mathrm{H}$ aromatic stretching vibration at 3060 and $3025 \mathrm{~cm}^{-1}$, the $\mathrm{C}-\mathrm{H}$ stretching vibration at $2924 \mathrm{~cm}^{-1}$, and the phenyl ring stretching vibration were at $1602,1494,1450,700$, and $760 \mathrm{~cm}^{-1}$ where the typical absorption bands for polystyrene were clearly observed [10], indicating that the silver nanoparticles have been successfully encapsulated within the polystyrene using miniemulsion polymerization. The methacrylic acid added to minimize interactions between the polymer particles and give colloidal stability is physically absorbed onto the surface of the polymer particles; besides, there are also chemical 
TABLE 1: The encapsulation efficiency, conversion, and average particle diameter for the polymerizations systems.

\begin{tabular}{lcccccc}
\hline Sample & {$[\mathrm{I}]\left(\mathrm{g} / \mathrm{L}\right.$ of $\left.\mathrm{H}_{2} \mathrm{O}\right)$} & {$[\mathrm{S}]\left(\mathrm{g} / \mathrm{L}\right.$ of $\left.\mathrm{H}_{2} \mathrm{O}\right)$} & {$[\mathrm{HD}]\left(\mathrm{g} / \mathrm{L}\right.$ of $\left.\mathrm{H}_{2} \mathrm{O}\right)$} & \%EE & $\% \mathrm{C}$ & $\mathrm{D}(\mathrm{nm})$ \\
\hline 1 & 0.7 & 6.25 & 6.25 & 13.73 & 79 & $75.73 \pm 4.83$ \\
2 & 2.5 & & & 14.15 & 88 & $64.17 \pm 1.27$ \\
\hline
\end{tabular}

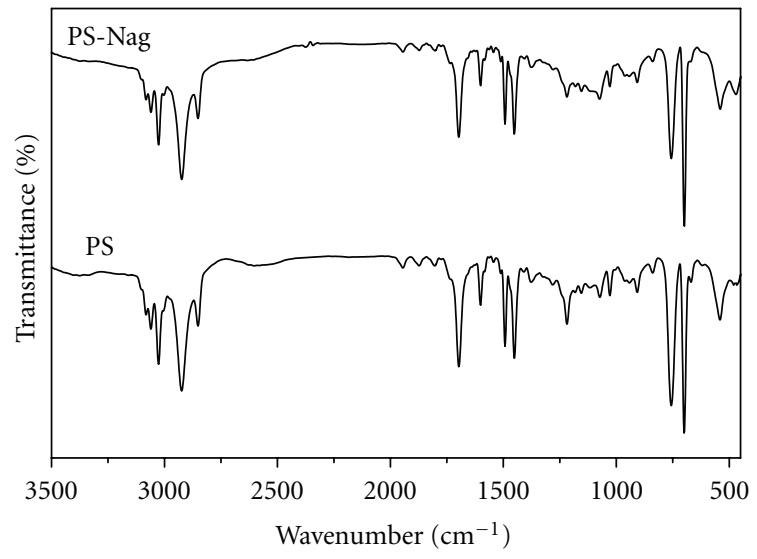

FIGURE 3: FTIR spectrum of PS and PS-Nag nanocomposite.

interactions in styrene molecules forming covalent bonds that result in a graft copolymer. The nanocomposite of PS/modified Nag shows a band in $1700 \mathrm{~cm}^{-1}$, this can be attributed to carbonyl stretching of carboxyl group indicating the copolymerization of MAA and St.

Figure 4 shows a typical SEM image of the PS-Nag nanocomposites. All particles show spherical morphology. The silver nanoparticles are visible as dark spots inside the polystyrene particles with sizes in the range of approximately 50 and $100 \mathrm{~nm}$. The SEM image shows that the encapsulation of the NAg into the polymer matrix is complete; no free NAg was observed. The particle size distribution (Figure 5) was obtained by measuring the diameter of a number of particles close to 300 . The particle size for the sample obtained using $[\mathrm{I}]=0.7 \mathrm{~g} / \mathrm{L}$ was $75.73 \mathrm{~nm}$ and $64.17 \mathrm{~nm}$ when $[\mathrm{I}]$ was $2.5 \mathrm{~g} / \mathrm{L}$. From this figure it can be concluded that when the initiator concentration $[\mathrm{I}]$ is increased, a significant change in particle size of the PS-Nag nanocomposite can be distinguished. This could be attributed to the higher stability achieved during the polymerization reaction.

The antimicrobial activity of the PS-Nag nanocomposites was studied against E. coli and S. aureus as given in Table 2 . The growth of E. coli and S. aureus was affected significantly by PS-Nag nanocomposites compared to that of the control. The inhibitory zone around the control could not be observed. However, inhibitory zones could be seen clearly around the PS-Nag nanocomposites. Moreover, according to Table 2, the antibacterial activity of both nanocomposites against $E$. coli and $S$. aureus improved with increasing the amount of initiator. The inhibitory zone increased from $17 \%$ to $21 \%$ for E. coli and from $9 \%$ to $13 \%$ for S. aureus as the amount of initiator increased from 0.7 to $2.5 \mathrm{~g} / \mathrm{L}$. The nanocomposite with a higher concentration of initiator showed a higher \% inhibition for both microorganisms, this

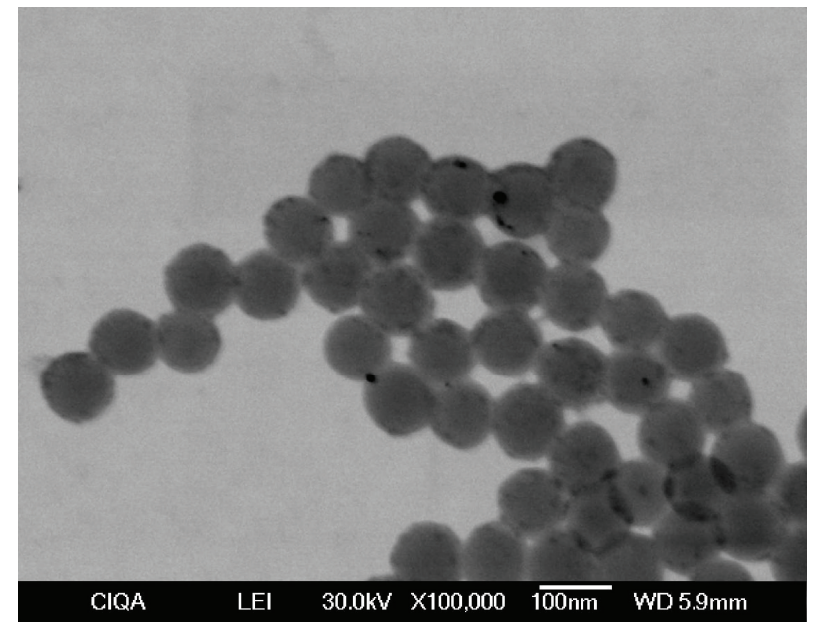

FIGURE 4: STEM micrograph of the PS-Nag nanocomposite.

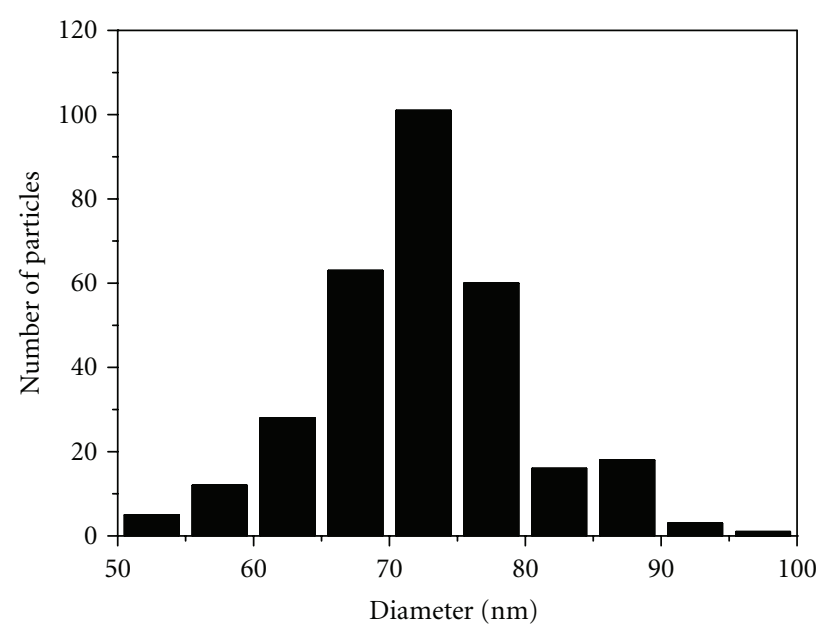

FIGURE 5: Particle size distribution of the PS-Nag nanocomposite.

behavior can be attributed to the size of particles as well as the $\%$ of silver in the nanocomposite. This means that the decrease in the number of colonies produced an increase in the biocide effect of the microorganisms.

\section{Conclusions}

In this work, the encapsulation of silver nanoparticles in a polymer matrix by miniemulsion polymerization was studied. The nanocomposites showed spherical morphology with diameters sizes ranged between 50 and $100 \mathrm{~nm}$. Importantly, the synthesized PS-Nag nanocomposites had an excellent biocidal potential against $E$. coli and $S$. aureus. According to these results, these nanocomposites can be used 
TABLE 2: The antimicrobial activity of the PS-NAg nanocomposites against E. coli and S. aureus.

\begin{tabular}{|c|c|c|c|c|c|c|}
\hline \multirow{2}{*}{ Sample } & \multirow{2}{*}{ [I] $\left(\mathrm{g} / \mathrm{L}\right.$ of $\left.\mathrm{H}_{2} \mathrm{O}\right)$} & \multicolumn{2}{|c|}{ Inhibition (\%) } & \multicolumn{2}{|c|}{ Colony formation units (CFU) $\left(\mathrm{ml}^{-1}\right) E-07$} & \multirow{2}{*}{$\% A g$} \\
\hline & & E. coli & S. aureus & E. coli & S. aureus & \\
\hline 1 & 0.7 & 17 & 9 & 2 & 1.68 & 0.17 \\
\hline 2 & 2.5 & 21 & 13 & 1.2 & 1.54 & 1.23 \\
\hline
\end{tabular}

in different applications such as clinical paints and coatings of biomedical materials.

\section{Acknowledgments}

The authors are thankful to CONACYT for the financial support to carry out this study through project SEP-2007CB87159. Also the authors wish to thank M. L. LopezQuintanilla, for assistance in the SEM characterization and Dra. A. R. Paredes for help in the antimicrobial activity tests.

\section{References}

[1] J. M. Yeh, C. L. Chen, C. C. Huang et al., "Effect of organoclay on the thermal stability, mechanical strength, and surface wettability of injection-molded ABS-clay nanocomposite materials prepared by melt intercalation," Journal of Applied Polymer Science, vol. 99, no. 4, pp. 1576-1582, 2006.

[2] J.-M. Yeh, S.-J. Liou, C.-Y. Lai, P.-C. Wu, and T.-Y. Tsai, "Enhancement of corrosion protection effect in polyaniline via the formation of polyaniline-clay nanocomposite materials," Chemistry of Materials, vol. 13, no. 3, pp. 1131-1136, 2001.

[3] S. Sánchez-Valdes, M. L. López-Quintanilla, E. RamírezVargas, F. J. Medellín-Rodríguez, and J. M. GutierrezRodriguez, "Effect of ionomeric compatibilizer on clay dispersion in polyethylene/clay nanocomposites," Macromolecular Materials and Engineering, vol. 291, no. 2, pp. 128-136, 2006.

[4] M. Zanetti, S. Lomakin, and G. Camino, "Fire retardancy of polymer," Chemistry of Materials, vol. 279, pp. 1-9, 2000.

[5] R. Zong, Y. Hu, S. Wang, and L. Song, "Thermogravimetric evaluation of $\mathrm{PC} / \mathrm{ABS} /$ montmorillonite nanocomposite," Polymer Degradation and Stability, vol. 83, no. 3, pp. 423-428, 2004.

[6] T. N. Kim, Q. L. Feng, J. O. Kim et al., "Antimicrobial effects of metal ions ( $\mathrm{Ag}+, \mathrm{Cu} 2+, \mathrm{Zn} 2+)$ in hydroxyapatite," Journal of Materials Science, vol. 9, no. 3, pp. 129-134, 1998.

[7] M. Uchida, "Antimicrobial zeolite and its application," Chemical Industry, vol. 46, pp. 48-54, 1995.

[8] M. M. da Silva Paula, C. V. Franco, M. C. Baldin et al., "Synthesis, characterization and antibacterial activity studies of poly-styrene-acrylic acid with silver nanoparticles," Materials Science and Engineering C, vol. 29, no. 2, pp. 647-650, 2009.

[9] Y. Boguslavsky and S. Margel, "Synthesis and characterization of poly(divinylbenzene)-coated magnetic iron oxide nanoparticles as precursor for the formation of air-stable carboncoated iron crystalline nanoparticles," Journal of Colloid and Interface Science, vol. 317, no. 1, pp. 101-114, 2008.

[10] E. Tang and S. Dong, "Preparation of styrene polymer/ZnO nanocomposite latex via miniemulsion polymerization and its antibacterial property," Colloid and Polymer Science, vol. 287, no. 9, pp. 1025-1032, 2009.

[11] S. N. Goyanes, J. D. Marconi, P. G. König, G. H. Rubiolo, C. L. Matteo, and A. J. Marzocca, "Analysis of thermal diffusivity in aluminum (particle)-filled PMMA compounds," Polymer, vol. 42, no. 12, pp. 5267-5274, 2001.

[12] H. Kawaguchi, "Functional polymer microspheres," Progress in Polymer Science, vol. 25, no. 8, pp. 1171-1210, 2000.

[13] K. Landfester, "Synthesis of colloidal particles in miniemulsions," Annual Review of Materials Research, vol. 36, pp. 231279, 2006.

[14] Y. Luo and X. Zhou, "Nanoencapsulation of a hydrophobic compound by a miniemulsion polymerization process," Journal of Polymer Science, Part A, vol. 42, no. 9, pp. 2145-2154, 2004.

[15] S. Sajjadi and F. Jahanzad, "Comparative study of monomer droplet nucleation in the seeded batch and semibatch miniemulsion polymerisation of styrene," European Polymer Journal, vol. 39, no. 4, pp. 785-794, 2003.

[16] K. Landfester, "Polyreactions in miniemulsions," Macromolecular Rapid Communications, vol. 22, no. 12, pp. 896-936, 2001.

[17] S. W. Zhang, S. X. Zhou, Y. M. Weng, and L. M. Wu, "Synthesis of $\mathrm{SiO}_{2} /$ polystyrene nanocomposite particles via miniemulsion polymerization," Langmuir, vol. 21, no. 6, pp. 2124-2128, 2005.

[18] F. Bouanani, D. Bendedouch, C. Maitre, J. Teixeira, and P. Hemery, "Characterization of miniemulsion polymerization by small-angle neutron scattering," Polymer Bulletin, vol. 55, no. 6, pp. 429-436, 2005.

[19] J. M. Asua, "Miniemulsion polymerization," Progress in Polymer Science, vol. 27, no. 7, pp. 1283-1346, 2002.

[20] M. J. MacLachlan, I. Manners, and G. A. Ozin, "New (inter)faces: polymers and inorganic materials," Advanced Materials, vol. 12, no. 9, pp. 675-681, 2000.

[21] E. Tang, G. Cheng, and X. Ma, "Preparation of nano$\mathrm{ZnO} / \mathrm{PMMA}$ composite particles via grafting of the copolymer onto the surface of zinc oxide nanoparticles," Powder Technology, vol. 161, no. 3, pp. 209-214, 2006.

[22] O. S. Rodríguez, F. Y. Castellanos, R. Betancourt, and I. G. Yañez, "A new class of polyvinylcloride nanocomposite based on magnetic nanofillers and plastisols," in Proceedings of the 67th Annual Technical Conference of the Society of Plastics Engineers (ANTEC'09), pp. 438-441, June 2009.

[23] E. Iglesias-Silva, J. Rivas, L. M. León Isidro, and M. A. LópezQuintela, "Synthesis of silver-coated magnetite nanoparticles," Journal of Non-Crystalline Solids, vol. 353, no. 8-10, pp. 829831, 2007.

[24] K. Landfester, "Miniemulsion polymerization and the structure of polymer and hybrid nanoparticles," Angewandte Chemie-International Edition, vol. 48, no. 25, pp. 4488-4508, 2009.

[25] S. K. Ghosh, Functional Coatings by Polymer Microencapsulation, Wiley-VCH, Weinheim, Germany, 2006.

[26] D. Urban and K. Takamura, Polymer Dispersions and Their Industrial Applications, Wiley-VCH, Weinheim, Germany, 2002.

[27] J. Brander and I. Thorn, Surface Application of Paper Chemicals, Blackie Academic \& Professional, AnImprint of Chapman \& Hall, 1997. 

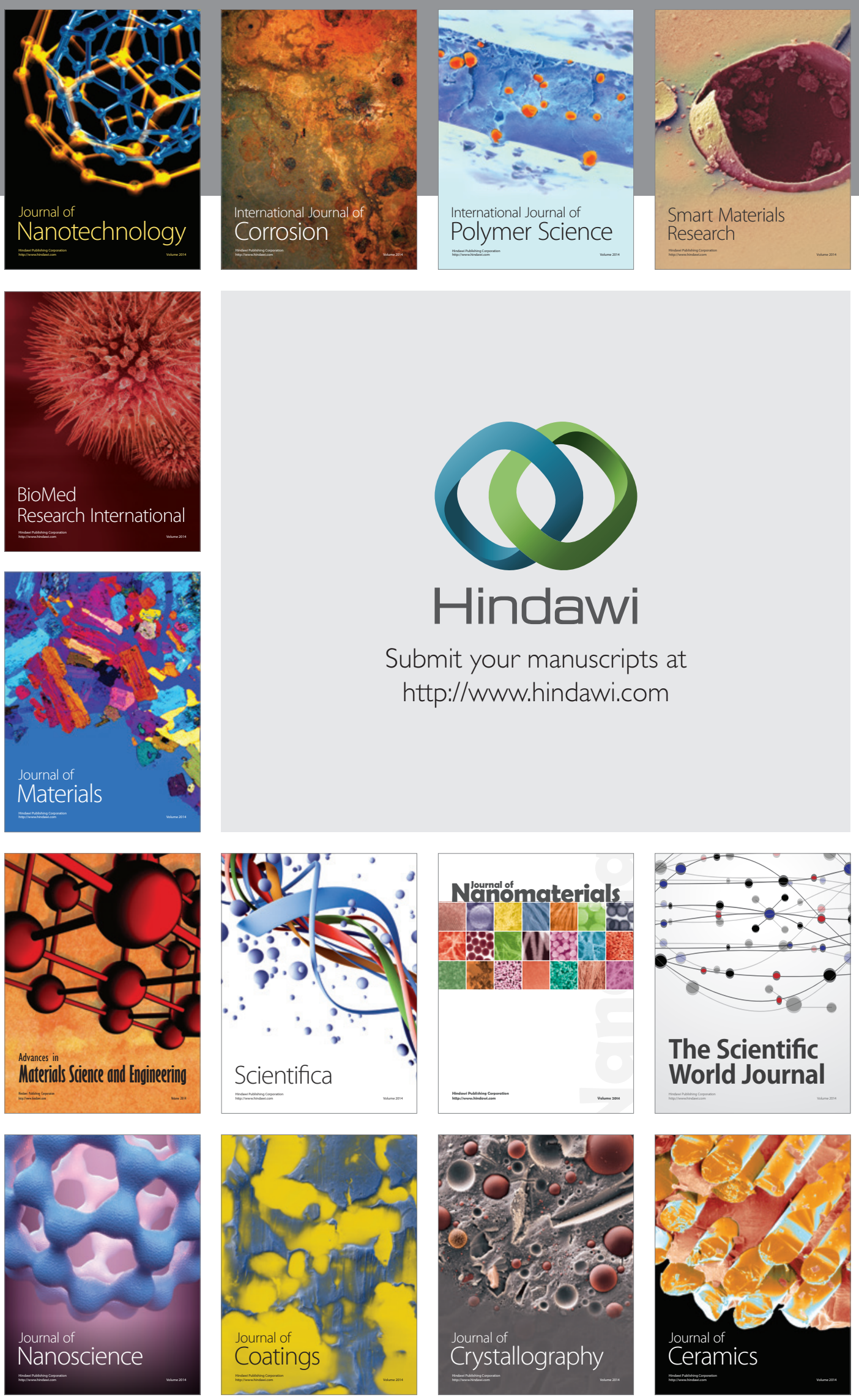

The Scientific World Journal

Submit your manuscripts at

http://www.hindawi.com

\section{World Journal}

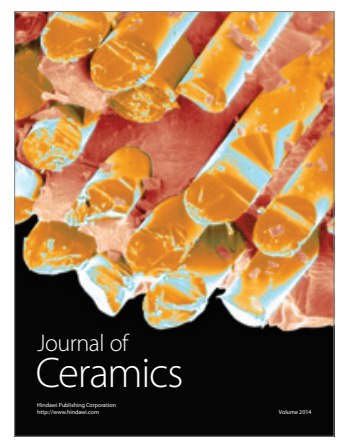

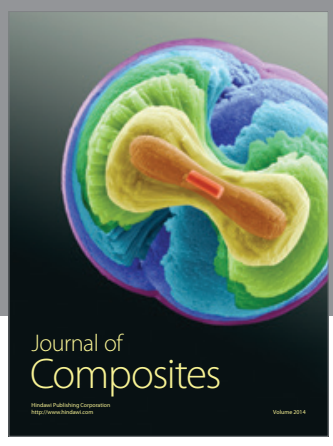
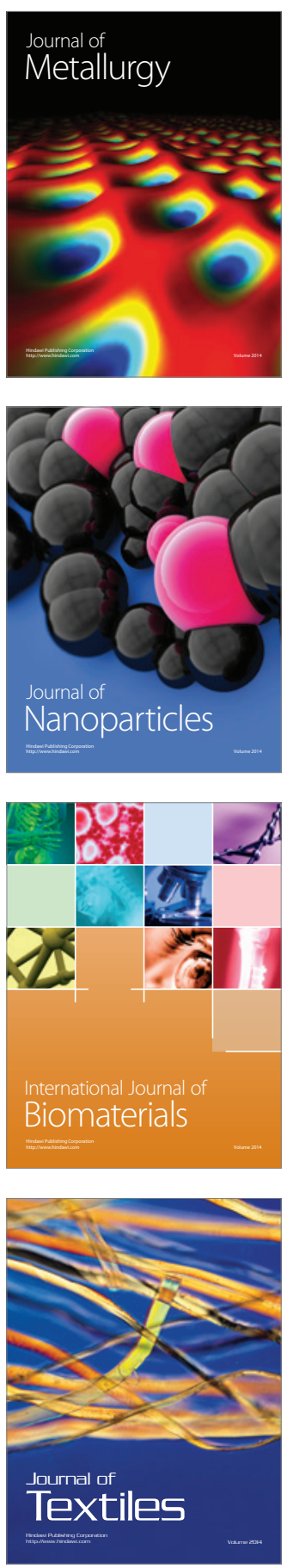